\title{
Who eats healthily? A population-based study among young Swiss residents
}

\author{
Marietta Meier, André Berchtold, Christina Akré, Pierre-André Michaud and \\ Joan-Carles Surís* \\ Research Group on Adolescent Health, Institute of Social and Preventive Medicine, Centre Hospitalier \\ Universitaire Vaudois and University of Lausanne, Bugnon 17, 1005 - Lausanne, Switzerland
}

Submitted 9 October 2009: Accepted 18 March 2010: First published online 4 May 2010

\begin{abstract}
Objective: To assess whether Swiss residents aged 15-24 years follow current nutritional guidelines and whether differences exist according to gender and weight status.

Design: Cross-sectional national survey.

Setting: Switzerland.

Subjects: The 1786 participants (48.4\% women) were divided into overweight, normal weight and underweight. We used traditional BMI cut-offs for people $\geq 18$ years of age (underweight $=\mathrm{BMI}<18.5 \mathrm{~kg} / \mathrm{m}^{2}$, normal weight $=\mathrm{BMI} \geq 18.5 \mathrm{~kg} / \mathrm{m}^{2}$ and $<25 \mathrm{~kg} / \mathrm{m}^{2}$, overweight $=\mathrm{BMI} \geq 25 \mathrm{~kg} / \mathrm{m}^{2}$ ) and age- and gender-appropriate tables for people aged $<18$ years, with BMI calculated from self-reported weight and height. We performed bivariate analyses by gender, and then bivariate and multivariate analyses comparing overweight to normal weight people (excluding underweight, $n 129,71 \cdot 6 \%$ women) regarding adherence to recommendations for fruit, vegetables, meat, fish and dairy products; physical activity; attitude towards body weight; depression, smoking and alcohol consumption.

Results: Overall, adherence to nutritional guidelines was low, particularly for vegetables and dairy products. Women had a higher adherence than men except for fish and dairy products. In the multivariate analyses, overweight women had a lower vegetable intake, were less satisfied with body weight and had more often been on a diet, whereas overweight men were less satisfied with body weight and wanted to lose weight more often than their normal weight peers. There were no significant differences for physical activity.

Conclusions: Overweight prevention programmes should target youth specifically by gender and promote an appropriate self-perception. Overweight women should be encouraged to eat more vegetables and men to be more sensitised on healthy food. Further research is needed to assess how to make nutritional guidelines more adaptable to young people's daily life.
\end{abstract}

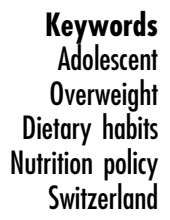

Adolescent Overweight Dietary habits Switzerland
Overweight and obesity have increased during the last few decades in Switzerland as in many other Western countries. In Switzerland, the number of overweight people aged 15-74 years increased from $24.9 \%$ in 1992 to $29 \cdot 4 \%$ in $2002^{(1)}$. The long-term consequences of obesity are numerous. It is a well-known risk factor for type 2 diabetes mellitus ${ }^{(2)}, \mathrm{CVD}^{(3,4)}$ and for increased death rates of cancer ${ }^{(3,5)}$. Accordingly, general and abdominal adiposity are associated with a higher risk of death ${ }^{(6)}$.

More and more children and adolescents are overweight $^{(7,8)}$ and the prevalence of type 2 diabetes, which has traditionally been considered a disease for middleaged and elderly adults, has increased considerably among adolescents and children ${ }^{(9)}$. In addition, food habits adopted in childhood and adolescence are likely to extend into adulthood ${ }^{(10)}$ and overweight adolescents have a twofold greater risk for being overweight as adults $^{(11)}$. Consequently, it is of great importance to prevent excessive weight gain in adolescents and to identify associated factors that are amenable to intervention and preventive actions.

Lifestyle changes towards energy-rich food at the expense of fruit and vegetables and reduction of daily physical activity have resulted in an imbalance between energy intake and expenditure and finally in a weight gain $^{(12)}$. A negative trend in daily fruit and vegetable consumption among Swiss residents aged 15-24 years has been reported ${ }^{(13)}$, and a clear decrease in sports activity, more marked in women (82-69\%) than in men (86-79\%), has been observed among Swiss adolescents between 
1993 and $2002^{(14)}$. A major obstacle for physical activity is dissatisfaction with body weight in women, but not in men ${ }^{(15)}$. In fact, overweight women are stigmatised to a higher degree than men and peer victimisation is a barrier to physical activity ${ }^{(16)}$.

The Swiss Society for Nutrition ${ }^{(17)}$ recommends two portions of fruits, three portions of vegetables and three portions of dairy products every day. No more than five portions of meat and at least one portion of fish should be consumed per week. These recommendations are in agreement with the WHO diet guidelines ${ }^{(18)}$. Although a low adherence to nutritional guidelines has been reported in other countries ${ }^{(19-21)}$, to our knowledge, it has never been investigated whether Swiss resident youth follow the current recommendations for nutrition.

The aims of our study are to assess the extent to which Swiss residents aged 15-24 years follow the current nutritional guidelines and whether differences exist between overweight and normal weight people concerning adherence to these guidelines. In addition, we compare overweight and normal weight youth regarding physical activity and attitude towards body weight, because these are important factors related to weight differences ${ }^{(15,22)}$.

We hypothesise (i) that only a minority completely fulfil the nutritional recommendations, since a low adherence to current nutritional guidelines has been reported in other countries $^{(19-21)}$ and (ii) that overweight youth follow the guidelines to a lower extent than do normal weight youth.

\section{Methods}

\section{Population}

Data were derived from The Swiss Health Survey 2007, a nationally representative survey of Swiss residents aged 15 years or more ( $n 18760$, response rate $66 \%$ ), conducted by the Swiss Federal Statistical Office every 5 years. The study sample was chosen by stratified random sampling of a database of all private Swiss households with a landline telephone connection. Stratification was made by region, canton and household. The number of households was proportionate to the population of the canton.

Telephone interviews were conducted during 2007 in order to obtain results taking into account seasonal variations. One member of each household was randomly selected and received an invitation letter to participate in the survey. The selected person was questioned either by computer-assisted telephone interview or face-to-face for people over 74 years, if preferred. The interview was carried out in French, German and Italian, the three most used national languages of Switzerland. If the selected person was absent or unable to answer for linguistic or medical reasons, the interview was conducted by proxy. The participants were then asked to complete an additional written questionnaire. Data were assessed using a computer-assisted telephone interview.

\section{Dependent variable}

For our study, we used data from people aged 15-24 years completing the telephone interview, excluding twelve men and fifteen women not reporting their weight and height ( $n$ 1786, 48.4\% women). We divided the sample into three groups: overweight, normal weight and underweight using the BMI (weight $(\mathrm{kg}) /$ height $^{2}\left(\mathrm{~m}^{2}\right)$ ) that was calculated from self-reported weight and height. For people aged $\geq 18$ years, underweight was defined as a BMI $<18.5 \mathrm{~kg} / \mathrm{m}^{2}$, normal weight as a BMI $\geq 18.5 \mathrm{~kg} / \mathrm{m}^{2}$ and $<25 \mathrm{~kg} / \mathrm{m}^{2}$ and overweight as a BMI $\geq 25 \mathrm{~kg} / \mathrm{m}^{2}$. For people aged $<18$ years, groups were defined according to the tables of Kromeyer-Hauschild et $a l^{(23)}$ for age and sex. For our study, we first compared by gender, and then between overweight and normal weight people, excluding those who were underweight ( $n 129,71 \cdot 6 \%$ women).

\section{Independent variables}

For dietary habits, participants were dichotomised according to whether they followed the current recommendations for nutrition ${ }^{(17,18)}$ or not. According to the possible answers in the questionnaire, we defined recommendations as at least one to two portions per day of fruit or fruit juice and at least three to four portions per day of vegetables or vegetable juice, considering a portion as the size of a fist $(\sim 120 \mathrm{~g})$. Meat and sausages should not be eaten more than five times a week and fish at least once a week. Three portions per day of milk or dairy products are recommended, defining a portion as either $200 \mathrm{~g}$ of cream cheese/cottage cheese or $30-60 \mathrm{~g}$ of hard cheese or a medium-sized cup of yoghurt.

To measure the level of physical activity, we created the variable physical activity leading to breathlessness by summing up the number of days per week on which participants were reported to be involved in such activity during at least $30 \mathrm{~min}$. Then the participants were dichotomised into involved in physical activity leading to breathlessness on at least 4 days a week or not, referring to the recommendation of moderate-intensity physical activity of at least $30 \mathrm{~min}$ on most days of the week ${ }^{(24,25)}$.

To analyse participants' attitude towards body weight, we used three dichotomous variables: satisfaction with body weight, wishing to lose weight and having been on a diet to lose weight during the past 12 months.

We also assessed several other factors that are known to be associated with overweight. Depressed adolescents have been shown to be at increased risk for the development and persistence of obesity during adolescence $^{(26)}$, and therefore we assessed the presence or absence of a major depressive disorder using the index of the Swiss Federal Statistical Office for major depressive disorder elaborated from the Composite International Diagnostic Interview Short From ${ }^{(27)}$. The dichotomous variable, daily smoker, was used to assess smoking habits, since a relationship between smoking and a higher risk for overweight has been shown ${ }^{(28)}$. As an association between overweight and alcohol consumption has been 
found in other studies ${ }^{(29,30)}$, we assessed alcohol consumption by classifying participants who had a daily alcohol consumption as daily drinkers, those who drank at least once a week (but not daily) as regular drinkers and those consuming less than once a week (including those who never drink) as light drinkers. No woman reported consuming alcohol every day, and therefore we only had two groups for women (regular and light drinkers).

Finally, we controlled for age, nationality (Swiss/other) and residence area (urban/rural) because these are potential confounders ${ }^{(31,32)}$.

\section{Statistics}

First, we performed a bivariate analysis to compare the adherence to nutritional guidelines between women and men. Then, bivariate analyses were performed with all factors involved to compare overweight to normal weight people (excluding those who were underweight), using $\chi^{2}$ tests to analyse categorical data and $t$ tests for continuous data. All analyses between overweight and normal weight youth were conducted separately by gender, because differences between men and women in exposure and vulnerability to risk factors for overweight have been reported $^{(33)}$. Given that standard procedures for automatic variable selection in regressions such as backward and stepwise selection are known to produce unstable and nonreproducible results ${ }^{(34)}$, we selected all important factors using a bootstrap procedure. A total of 1250 bootstrap samples were generated for women and for men and a backward selection procedure was applied on each of them. Variables retained in at least $60 \%$ of the replications were selected for inclusion in the logistic regression analysis $^{(35)}$. Results are given as adjusted OR (AOR) with 95\% CI using the normal weight group as the reference category.

We used the Stata 10 statistical software package (StataCorp LP, College Station, TX, USA) for bivariate and multivariate analyses (as it allows one to compute coefficient estimates and variances taking into account the sampling weights) and MATLAB 7·1 (The MathWorks Inc., Natick, MA, USA) for the bootstrap variable selection. Significance level was set at $0 \cdot 05$.

\section{Results}

\section{Bivariate analyses}

Comparing adherence to nutritional guidelines by gender There were significantly more women than men who followed the nutritional guidelines for fruit, vegetables and meat, whereas more men followed the recommendations for dairy products. There was no significant difference for the consumption of fish (Table 1).

\section{Overweight v. normal weight women}

In all, $8 \%$ of women were overweight ( $n$ 67). Compared to normal weight women, they were significantly older and consumed fewer vegetables. In fact, only $4 \cdot 2 \%$ reported
Table 1 Comparison of adherence to nutritional guidelines by gender

\begin{tabular}{lccc}
\hline & $\begin{array}{c}\text { Women } \\
(n \text { 865 })^{\star} \\
\%\end{array}$ & $\begin{array}{c}\text { Men } \\
(n \text { 921) } \\
\%\end{array}$ & $P$ \\
\hline Fruits $(\geq 1$ to 2 portions/d) & 88.35 & 76.76 & 0.0001 \\
Vegetables ( $\geq 3$ portions/d) & 16.68 & 11.15 & 0.0063 \\
Meat $(\leq 5$ times/week $)$ & 80.31 & 53.40 & 0.0001 \\
Fish ( $\geq 1$ times/week) & 53.95 & 53.26 & 0.8165 \\
Dairy products ( $\geq 3$ portions/d) & 10.05 & 18.35 & 0.0001 \\
\hline
\end{tabular}

*The sample size for each analysis varies between 812 and 865 due to missing data when questions were answered by proxy.

tThe sample size for each analysis varies between 860 and 921 due to missing data when questions were answered by proxy.

eating a minimum of three portions per day compared to $18.1 \%$ of those of normal weight. In contrast, there were no significant differences between the two groups for the intake of fruit, meat, fish and dairy products. In fact, dairy products consumption was very low in both groups, with only about $10.0 \%$ consuming three portions per day.

No difference was found for physical activity leading to breathlessness.

Concerning the attitude towards body weight, overweight women were significantly less satisfied with their body weight, more likely to wish to lose weight and had more often been on a diet.

There were no significant differences for depression, smoking and alcohol consumption (Table 2).

\section{Overweight v. normal weight men}

In all, $15 \%$ of men were overweight ( $n$ 139). They were significantly older, but there were no significant differences in the consumption of the diverse food categories. For both groups, the consumption of vegetables and dairy products was very low. Only $13 \cdot 4 \%$ of those who were overweight and $10 \cdot 7 \%$ who were of normal weight consumed the recommended amount of vegetables and dairy products $(17 \cdot 0 \%$ and $19 \cdot 2 \%$, respectively).

There was no difference between the two groups for physical activity leading to breathlessness.

Overweight men were significantly less satisfied with their body weight, more likely to wish to lose weight and had more often been on a diet than normal weight men.

We found no difference for depression and smoking, but there were significantly more overweight men $(11.6 \% v$. $1 \cdot 2 \%$ ) who reported consuming alcohol every day (Table 3 ).

\section{Multivariate analyses}

When controlling for possible confounders (age, nationality and residence area), overweight women still consumed less vegetables $(\mathrm{AOR}=0 \cdot 18(95 \% \mathrm{CI} 0 \cdot 05,0 \cdot 72))$, were less satisfied with their body weight $(\mathrm{AOR}=0 \cdot 11$ (95\% CI $0 \cdot 05,0 \cdot 24)$ ) and had more often been on a diet $(\mathrm{AOR}=3 \cdot 77(95 \%$ CI $1 \cdot 55,9 \cdot 20))$. Overweight men were less likely to be satisfied with their body weight $(\mathrm{AOR}=$ $0 \cdot 49(95 \%$ CI $0 \cdot 28,0 \cdot 87))$ and more likely to want to lose weight $(\mathrm{AOR}=10 \cdot 66(95 \% \mathrm{CI} 6 \cdot 00,18 \cdot 94)$; Table 4). 
Table 2 Comparison of adherence to nutritional guidelines, physical activity, attitude towards body weight and other obesity-associated factors between normal weight and overweight women

\begin{tabular}{|c|c|c|c|}
\hline Females & $\begin{array}{l}\text { Normal weight* } \\
\quad(n \text { 705) }\end{array}$ & $\begin{array}{l}\text { Overweight } \\
\quad(n 67)\end{array}$ & $P$ \\
\hline Mean age & $\begin{array}{c}19 \cdot 12 \\
\%\end{array}$ & $\begin{array}{c}20 \cdot 11 \\
\%\end{array}$ & 0.0213 \\
\hline Fruits ( $\geq 1$ to 2 portions/d) & $88 \cdot 81$ & $90 \cdot 51$ & $0 \cdot 6870$ \\
\hline Vegetablesł $(\geq 3$ portions/d) & 18.06 & $4 \cdot 16$ & 0.0049 \\
\hline Meat ( $\leq 5$ times/week) & $79 \cdot 61$ & $76 \cdot 47$ & 0.6047 \\
\hline Fish ( $\geq 1$ times/week) & $52 \cdot 68$ & $64 \cdot 06$ & $0 \cdot 1568$ \\
\hline Dairy products as recommended ( $\geq 3$ portions $/ \mathrm{d}$ ) & $9 \cdot 81$ & $10 \cdot 02$ & 0.9642 \\
\hline Physical activity leading to breathlessness & $25 \cdot 54$ & 14.99 & 0.0741 \\
\hline Satisfied with body weight & $71 \cdot 54$ & $18 \cdot 28$ & 0.0001 \\
\hline Wants to lose weight & $45 \cdot 65$ & $85 \cdot 56$ & 0.0001 \\
\hline Has been on a diet $\ddagger$ & $5 \cdot 23$ & $27 \cdot 64$ & 0.0001 \\
\hline Major depressive disorder & $8 \cdot 19$ & $7 \cdot 81$ & 0.9256 \\
\hline Daily smoker & $18 \cdot 66$ & $18 \cdot 11$ & 0.9246 \\
\hline Alcohol consumption & & & $0 \cdot 1527$ \\
\hline Light & 63.96 & $75 \cdot 13$ & \\
\hline Regular & $36 \cdot 04$ & $24 \cdot 87$ & \\
\hline
\end{tabular}

*The sample size for each analysis varies between 658 and 705 due to missing data when questions were answered by proxy. tThe sample size for each analysis varies between 62 and 67 due to missing data when questions were answered by proxy. $\ddagger$ Variables retained in at least $60 \%$ of replications in the bootstrap analysis (1250 replications).

Table 3 Comparison of adherence to nutritional guidelines, physical activity, attitude towards body weight and other obesity-associated factors between normal weight and overweight men

\begin{tabular}{|c|c|c|c|}
\hline Males & $\begin{array}{c}\text { Normal weight } \\
n 746^{*}\end{array}$ & $\begin{array}{c}\text { Overweight } \\
n 139+\end{array}$ & $P$ \\
\hline Mean age $\ddagger$ (years) & $\begin{array}{c}18 \cdot 92 \\
\%\end{array}$ & $\begin{array}{c}20 \cdot 41 \\
\%\end{array}$ & 0.0001 \\
\hline Fruits ( $\geq 1$ to 2 portions/d) & $76 \cdot 69$ & $78 \cdot 83$ & 0.6792 \\
\hline Vegetables ( $\geq 3$ portions/d) & $10 \cdot 74$ & $13 \cdot 43$ & 0.4932 \\
\hline Meat $(\leq 5$ times/week) & $54 \cdot 31$ & $48 \cdot 72$ & 0.3579 \\
\hline Fish ( $\geq 1$ times/week) & $52 \cdot 68$ & $59 \cdot 29$ & 0.2761 \\
\hline Dairy products ( $\geq 3$ portions/d) & $19 \cdot 15$ & $16 \cdot 98$ & 0.6571 \\
\hline Physical activity leading to breathlessness & $27 \cdot 83$ & $24 \cdot 57$ & 0.5487 \\
\hline Satisfied with body weight & $90 \cdot 65$ & $66 \cdot 49$ & 0.0001 \\
\hline Wants to lose weightł & $9 \cdot 15$ & $54 \cdot 65$ & 0.0001 \\
\hline Has been on a diet & $0 \cdot 70$ & $5 \cdot 02$ & 0.0030 \\
\hline Major depressive disorder & $4 \cdot 82$ & 8.05 & $0 \cdot 2194$ \\
\hline Daily smoker & $23 \cdot 55$ & $32 \cdot 00$ & $0 \cdot 1111$ \\
\hline Alcohol consumption & & & 0.0001 \\
\hline Light & $43 \cdot 72$ & $36 \cdot 70$ & \\
\hline Regular & $55 \cdot 04$ & $51 \cdot 67$ & \\
\hline Daily & $1 \cdot 24$ & $11 \cdot 64$ & \\
\hline
\end{tabular}

*The sample size for each analysis varies between 697 and 746 due to missing data when questions were answered by proxy. tThe sample size for each analysis varies between 124 and 139 due to missing data when questions were answered by proxy. $\ddagger$ Variables retained in at least $60 \%$ of replications in the bootstrap analysis (1250 replications).

It is interesting to note that some variables that were significant at the bivariate level (want to lose weight in women and has been on a diet in men) were not retained for the multivariate analysis by the bootstrap procedure. This indicates that these variables are too closely related to the particularities of our sample and that generalising the results to the entire population does not make sense. Thus, they were not included in the multivariate analysis.

\section{Discussion}

In our study population, the overall prevalence of overweight was $11.5 \%$, with more men $(15 \%)$ than womens
( $8 \%$ ) being overweight. This prevalence is similar to the national data reported among 20-year-olds in $2003^{(8)}$, but lower than other European data in similar age groups ${ }^{(36,37)}$, which also show higher prevalence rates for men than for women. The fact that our data were selfreported could explain these differences.

\section{Nutritional guidelines}

Confirming our first hypothesis, the adherence to current nutritional guidelines was generally low. Except for dairy products and fish, women had a higher adherence to nutritional guidelines than men. These results are in line with other studies that found women to have healthier eating patterns and stronger beliefs in healthy eating than 
Table 4 Results of the multivariate analysis comparing normal weight (reference category) and overweight youth after controlling for age, nationality and residence area

\begin{tabular}{|c|c|c|c|}
\hline & OR & $P>(t)$ & $95 \% \mathrm{Cl}$ \\
\hline \multicolumn{4}{|l|}{ Overweight women } \\
\hline Vegetables ( $\geq 3$ portions/d) & $0 \cdot 18$ & 0.016 & $0.05,0.72$ \\
\hline Satisfied with body weight & $0 \cdot 11$ & 0.001 & $0.05,0.24$ \\
\hline Has been on a diet & $3 \cdot 77$ & 0.004 & $1 \cdot 55,9 \cdot 20$ \\
\hline \multicolumn{4}{|l|}{ Overweight men } \\
\hline Satisfied with body weight & 0.49 & 0.015 & $0 \cdot 28,0.87$ \\
\hline Wants to lose weight & $10 \cdot 66$ & 0.001 & $6 \cdot 00,18 \cdot 94$ \\
\hline
\end{tabular}

men, and to be more likely to follow nutritional recommendations ${ }^{(38)}$. In addition, it has been suggested that some foods are gender-related. Meat, for example, represents strength and virility ${ }^{(39)}$ and might be therefore preferred by men, as in our study, where men were less likely to restrict their meat consumption to five or less portions a week as recommended.

Similar to our findings, other studies have already shown a lower dairy product consumption among women ${ }^{(19)}$, most likely because they are considered energy-rich. As women more often tend to have unhealthy weight-control behaviours than men, they are at increased risk for dietary inadequacy leading to a decreased intake of nutrients such as iron and calcium ${ }^{(40)}$. Men had a higher consumption of dairy products than women, but their consumption was nevertheless very low. The fact that so few participants were consuming the recommended amount of dairy products is of great concern. An adequate calcium intake is a protective factor for osteoporosis and adolescence and early adulthood is a crucial time for maximising the physiological potential for bone mineralisation ${ }^{(41)}$. During the transition from adolescence to adulthood, a decrease in daily intake of calcium has been reported in a recent longitudinal study ${ }^{(42)}$. Hence, nutrition intervention programmes are needed to increase dairy product intake among young people.

The overall low consumption of vegetables is in accordance with other studies in which only $40 \%$ of US children and adults ate an average of five portions of fruit and vegetables a day ${ }^{(21)}$ and fewer than one in ten adolescents and adults met their energy-specific MyPyramid fruit or vegetable recommendations ${ }^{(20)}$.

Overweight women had the lowest vegetable consumption of all. A similar result was found in another study in which an association between low vegetable consumption and high BMI was found in women, but not in men ${ }^{(43)}$. However, the role of fruit and vegetables in the prevention of overweight is not clearly established. A review of the epidemiological literature for children and adults showed that some studies found an association between high fruit and vegetable consumption and low BMI, whereas others had not found such an association $^{(44)}$. Nevertheless, the low vegetable intake among overweight women in our study could be an indicator for a generally different eating pattern, with low vegetable consumption as part of an energy-rich diet leading to overweight.

Given the overall low vegetable consumption, the question comes up whether the recommended three portions per day are feasible. The literature indicates a positive impact of fruit and vegetables on health, diminishing CVD and certain types of cancer ${ }^{(45)}$, as well as an inverse association with stroke, blood pressure and diabetes mellitus ${ }^{(46)}$. However, to fulfil the recommendations, fruit and vegetables have to be integrated consciously in the daily diet, perhaps a particularly difficult issue for young people. The consumption of fruit is higher, probably because they are often eaten between meals. Fruits can be consumed without preparation, while many vegetables have to be cooked or somehow prepared before eating. Moreover, their preparation demands more cooking skills and time, ${ }^{(47)}$ and therefore vegetable consumption seems probably less time- and cost-effective for young people than pre-cooked foods. In addition, it may also be that vegetables are not among the preferred tastes of young people. In fact, it has been reported that the recommended healthy foods are more expensive than energy-dense sweet and fat foods ${ }^{(48)}$. A diet according to the current nutritional guidelines is therefore more expensive than an unhealthy one and this is probably an additional barrier for young people to consume healthy food. Further research is needed to assess how to make nutritional guidelines for fruit and vegetables more adaptable to young people's daily life.

Our second hypothesis that overweight people had a lower adherence to nutritional guidelines than normal weight people was not confirmed. In fact, there were no significant differences in the adherence to nutritional guidelines between overweight and normal weight youth, apart from the lower vegetable consumption for overweight women. This result could be explained by current theories of inter-individual genotypic differences in susceptibility to overweight. In fact, it has been shown ${ }^{(49)}$ that there are large individual differences in the responsiveness to energy-balance manipulations, making certain genotypes more sensitive to weight gain than others.

\section{Physical activity}

As in other studies ${ }^{(14,50)}$ we found women to have a lower level of physical activity than men. Gender-related perceived benefits and barriers to physical activity have been largely described in the literature: for women, important motives for physical activity are to stay in shape and to be healthier, whereas for men it is mostly to improve athletic skills $^{(51)}$. Body dissatisfaction was shown to be the major barrier to physical activity in women but not in men ${ }^{(15)}$.

Surprisingly, there were no significant differences between overweight and normal weight in either gender regarding the level of physical activity leading to breathlessness. Nevertheless, we believe that this result does not allow us to conclude that overweight and normal weight 
people in our study had the same level of physical activity. It has been described in the literature that even a modest increase in body weight significantly worsens exercise performance ${ }^{(52)}$ and therefore overweight people become breathless more easily. However, an association between overweight and physical activity has not constantly been shown in the literature. Deforche et al. $^{(22)}$ showed that overweight and obese adolescents had a lower sports participation and Ekelund et al. ${ }^{(53)}$ found physical activity to be related to BMI in men, but not in women. These contradictory findings could also be due to methodological differences, as self-reported physical activity is likely to be different from objectively measured physical activity and overweight women in particular tend to over-report their physical activity level ${ }^{(54)}$.

\section{Attitude towards body weight}

In our study, more overweight than normal weight men wished to lose weight, but they had not been on a diet more often. In fact, dieting is known to be more common in women than in men ${ }^{(55)}$, and gender differences in weight-control behaviour are probably related to the fact that men have less knowledge of nutritional recommendations and are less aware of the association between nutrition and health than women ${ }^{(39)}$.

Although more overweight than normal weight men were dissatisfied with their body weight, there was also an important number of overweight men satisfied with their weight. In fact, more than two-thirds of men who were actually overweight reported being satisfied with their body weight. These results are in line with previous studies, indicating that men are likely to underestimate their weight status and that overweight prevention programmes possibly failed because overweight men did not realise the need to change their lifestyle to lose weight ${ }^{(56)}$.

Thus, misperception of weight status is an important factor that has to be taken into account when elaborating health policies.

Women, on the other hand, are more at risk for overestimating their weight status and might be therefore more prone to unnecessary dieting ${ }^{(57)}$. In our study, about three in ten normal weight women were dissatisfied with their body weight and $45 \cdot 7 \%$ of normal weight women wished to lose weight. As dieting increases the risk for disordered eating, and body dissatisfaction is related to physical inactivity, these women are probably at greater risk for developing disordered eating or overweight ${ }^{(15)}$.

\section{Depression, smoking and alcobol consumption}

Contrary to other studies ${ }^{(26,28)}$, we found no association between overweight and depression and smoking. In the bivariate analysis, daily alcohol consumption was significantly higher among men, in line with other studies reporting heavy alcohol intake to be positively related to overweight and obesity ${ }^{(29)}$. In our study, however, daily alcohol consumption did not stay significant after controlling for possible confounders in the multivariate analysis.

\section{Strengtb and limitations}

The main strength of our study is that it is based on a nationally representative sample of Swiss resident youth that allowed us to take into account all socio-economic backgrounds. However, there are some limitations. First, its cross-sectional design does not allow for causal analysis. Second, there were no questions about beverages and snacking, and therefore it was not possible to analyse the whole eating pattern. Third, data were self-reported, which could lead to bias, especially for weight and height. Paccaud et al. showed that, on average, weight was lower and height was greater than measured, leading to an underestimation of BMI when self-reported ${ }^{(58)}$. In addition, about $1.5 \%$ were excluded from our study because they did not report height or weight and it has recently been shown among schoolchildren that those with missing values for BMI tended to have a poorer body image and poorer health behaviours ${ }^{(59)}$. Finally, socially desirable answers cannot be excluded as a source of bias.

\section{Conclusions}

The overall adherence to nutritional guidelines was low, in particular for dairy products and vegetables. As dairy products are especially important for young people, additional research should assess how to increase their consumption. We assume that an intake of three portions of vegetables a day is difficult for young people, and therefore further research is needed to explore how nutritional guidelines could be better adapted to young people's daily life.

Clinicians should keep in mind that it is not only overweight youth who are at risk for unhealthy eating patterns and dieting, but also their normal weight peers, especially women. A balanced diet with a sufficient amount of vegetables and dairy products has to be encouraged.

From a public health point of view, prevention programmes to fight overweight should target youth specifically by gender. Overweight women should be encouraged to eat more vegetables, whereas men should generally be sensitised about healthy food. Furthermore, health professionals should help young people develop a better view of their own weight status. Certainly, the first step towards a healthy weight-control behaviour is an appropriate self-perception.

\section{Acknowledgements}

The Swiss Health Survey is funded by the Swiss Federal Statistical Office. The study received no additional funding. The funding body had no role in the design and conduct of the study, in the analysis and interpretation 
of the data or in the preparation, review or approval of the manuscript. The authors declare no conflict of interest. M.M., J.-C.S., C.A., A.B. and P.-A.M. designed the study. The Swiss Federal Statistical Office helped the implementation and co-ordination of the Swiss Health Survey and the data were collected by the MIS-Trend SA Institute, Lausanne, Switzerland. M.M., A.B. and J.-C.S. analysed and interpreted the data. M.M. and J.-C.S. were responsible for drafting of the manuscript. J.-C.S., C.A., A.B. and P.-A.M. did the critical revision of the manuscript. Statistical analyses were performed by M.M., A.B. and J.-C.S.

\section{References}

1. Eichholzer M, Bernasconi F, Jordan P et al. (2005) [Nutrition in Switzerland 2002 - results of the Swiss Health Survey]. Praxis (Bern 1994) 94, 1713-1721.

2. Golay A \& Ybarra J (2005) Link between obesity and type 2 diabetes. Best Pract Res Clin Endocrinol Metab 19, 649-663.

3. Kopelman PG (2000) Obesity as a medical problem. Nature 404, 635-643.

4. Mathew B, Francis L, Kayalar A et al. (2008) Obesity: effects on cardiovascular disease and its diagnosis. J Am Board Fam Med 21, 562-568.

5. Calle EE, Rodriguez C, Walker-Thurmond K et al. (2003) Overweight, obesity, and mortality from cancer in a prospectively studied cohort of US adults. $N$ Engl $J$ Med 348, 1625-1638.

6. Pischon T, Boeing H, Hoffmann K et al. (2008) General and abdominal adiposity and risk of death in Europe. $N$ Engl J Med 359, 2105-2120.

7. Adair LS (2008) Child and adolescent obesity: epidemiology and developmental perspectives. Physiol Behav 94, 8-16.

8. Mohler-Kuo M, Wydler H, Zellweger U et al. (2006) Differences in health status and health behaviour among young Swiss adults between 1993 and 2003. Swiss Med Wkly 136, 464-472.

9. Shaw J (2007) Epidemiology of childhood type 2 diabetes and obesity. Pediatr Diabetes 8, 7-15.

10. Mikkila V, Rasanen L, Raitakari OT et al. (2004) Longitudinal changes in diet from childhood into adulthood with respect to risk of cardiovascular diseases: the cardiovascular risk in Young Finns Study. Eur J Clin Nutr 58, 1038-1045.

11. Must A (1996) Morbidity and mortality associated with elevated body weight in children and adolescents. $A m J$ Clin Nutr 63, S445-S447.

12. Stubbs CO \& Lee AJ (2004) The obesity epidemic: both energy intake and physical activity contribute. Med J Aust 181, 489-491.

13. Roland C, Marilina G-P, Renaud L et al. (2009) Santé et comportements vis-à-vis de la santé en Suisse 1992-2002 Enquête suisse sur la santé. http://www.bfs.admin.ch/bfs/ portal/fr/index/themen/14/22/publ.Document.65198.pdf (accessed April 2009).

14. Suris JC, Michaud PA, Chossis I et al. (2006) Towards a sedentary society: trends in adolescent sport practice in Switzerland (1993-2002). J Adolesc Health 39, 132-134.

15. Haines J \& Neumark-Sztainer D (2006) Prevention of obesity and eating disorders: a consideration of shared risk factors. Health Educ Res 21, 770-782.

16. Tang-Peronard JL \& Heitmann BL (2008) Stigmatization of obese children and adolescents, the importance of gender. Obes Rev 9, 522-534.
17. Societé Suisse de Nutrition (2008) Recommandations nutritionnelles. http://www.sge-ssn.ch/fileadmin/pdf/100ernaehrungsthemen/70-altersspezifische_ernaehrung/2-kinder/ Merkblatt_Ernaehrung_von_Kindern.pdf (accessed April 2009).

18. World Health Organization (2003) Introduction. In Diet, Nutrition and the Prevention of Chronic Diseases. WHO Technical Report Series no. 916. Geneva: WHO.

19. Neumark-Sztainer D, Story M, Hannan PJ et al. (2002) Overweight status and eating patterns among adolescents: where do youths stand in comparison with the Healthy People 2010 objectives? Am J Public Health 92, 844-851.

20. Kimmons J, Gillespie C, Seymour J et al. (2009) Fruit and vegetable intake among adolescents and adults in the United States: percentage meeting individualized recommendations. Medscape J Med 11, 26.

21. Guenther PM, Dodd KW, Reedy J et al. (2006) Most Americans eat much less than recommended amounts of fruits and vegetables. J Am Diet Assoc 106, 1371-1379.

22. Deforche BI, De Bourdeaudhuij IM \& Tanghe AP (2006) Attitude toward physical activity in normal-weight, overweight and obese adolescents. J Adolesc Health 38, 560-568.

23. Kromeyer-Hauschild K, Wabitsch M, Kunze D et al. (2001) Percentiles of body mass index in children and adolescents evaluated from different regional German studies. Monatsschr Kinderbeilkd 149, 807-818.

24. US Department of Agriculture \& Department of Health and Human Services (2009) Dietary Guidelines for Americans 2005. http://www.health.gov/dietaryguidelines/dga2005/ document/pdf/DGA2005.pdf (accessed May 2009).

25. Martin-Diener E (2009) Gesundheitswirksame Bewegung. Bundesamt für Sport Magglingen BASPO, editor. http:// www.children-on-the-move.ch/dateien/dokumentation/ GD_Gesundheitswirks_Bewegung_2006.pdf (accessed May 2009).

26. Goodman E \& Whitaker RC (2002) A prospective study of the role of depression in the development and persistence of adolescent obesity. Pediatrics 110, 497-504.

27. Kessler RC, Andrews G, Mroczek D et al. (1998) The World Health Organization's Composite International Diagnostic Interview Short From (CIDI-SF). Int J Methods Psychiatr Res 7, 171-185.

28. Fasting MH, Nilsen TI, Holmen TL et al. (2008) Life style related to blood pressure and body weight in adolescence: cross sectional data from the Young-HUNT study, Norway. BMC Public Health 8, 111.

29. Croezen S, Visscher TL, Ter Bogt NC et al. (2009) Skipping breakfast, alcohol consumption and physical inactivity as risk factors for overweight and obesity in adolescents: results of the E-MOVO project. Eur J Clin Nutr $\mathbf{6 3}$, 405-412.

30. Schroder H, Morales-Molina JA, Bermejo S et al. (2007) Relationship of abdominal obesity with alcohol consumption at population scale. Eur J Nutr 46, 369-376.

31. Gordon-Larsen P, Adair LS, Nelson MC et al. (2004) Five-year obesity incidence in the transition period between adolescence and adulthood: the National Longitudinal Study of Adolescent Health. Am J Clin Nutr 80, 569-575.

32. Kumanyika SK (2008) Environmental influences on childhood obesity: ethnic and cultural influences in context. Physiol Behav 94, 61-70.

33. Sweeting HN (2008) Gendered dimensions of obesity in childhood and adolescence. Nutr J 14, 7.

34. Austin PC \& Tu JV (2004) Automated variable selection methods for logistic regression produced unstable models for predicting acute myocardial infarction mortality. J Clin Epidemiol 57, 1138-1146.

35. Austin PC \& Tu JV (2004) Bootstrap methods for developing predictive models. Am Stat 58, 131-137. 
36. Leyk D, Ruther T, Wunderlich M et al. (2008) Sporting activity, prevalence of overweight, and risk factors: crosssectional study of more than 12500 participants aged 16 to 25 years. Dtsch Arztebl Int 105, 793-800.

37. Garcia-Alvarez A, Serra-Majem L, Ribas-Barba L et al. (2007) Obesity and overweight trends in Catalonia, Spain (19922003): gender and socio-economic determinants. Public Health Nutr 10, 1368-1378.

38. Wardle J, Haase AM, Steptoe A et al. (2004) Gender differences in food choice: the contribution of health beliefs and dieting. Ann Behav Med 27, 107-116.

39. Kiefer I, Rathmanner T \& Kunz M (2005) Eating and dieting differences in men and women. J Mens Health Gender 2 , 194-201.

40. Neumark-Sztainer D, Hannan PJ, Story M et al. (2004) Weight-control behaviors among adolescent girls and boys: implications for dietary intake. J Am Diet Assoc 104, 913-920.

41. Lytle LA \& Kubik MY (2003) Nutritional issues for adolescents. Best Pract Res Clin Endocrinol Metab 17, 177-189.

42. Larson NI, Neumark-Sztainer D, Harnack L et al. (2009) Calcium and dairy intake: longitudinal trends during the transition to young adulthood and correlates of calcium intake. J Nutr Educ Behav 41, 254-260.

43. te Velde SJ, Twisk JW \& Brug J (2007) Tracking of fruit and vegetable consumption from adolescence into adulthood and its longitudinal association with overweight. Br J Nutr 98, 431-438.

44. Tohill BC, Seymour J, Serdula M et al. (2004) What epidemiologic studies tell us about the relationship between fruit and vegetable consumption and body weight. Nutr Rev 62, 365-374.

45. Heber D (2004) Vegetables, fruits and phytoestrogens in the prevention of diseases. J Postgrad Med 50, 145-149.

46. Bazzano LA (2006) The high cost of not consuming fruits and vegetables. J Am Diet Assoc 106, 1364-1368.

47. Kristjansdottir AG, Thorsdottir I, De Bourdeauhuij I et al (2006) Determinants of fruit and vegetable intake among 11-year-old schoolchildren in a country of traditionally low fruit and vegetable consumption. Int J Behav Nutr Phys Act 3, 41 .

48. Monsivais P \& Drewnowski A (2007) The rising cost of lowenergy-density foods. J Am Diet Assoc 107, 2071-2076.

49. Bouchard C (2008) Gene-environment interactions in the etiology of obesity: defining the fundamentals. Obesity (Silver Spring) 16, S5-S10.

50. Cavadini C, Decarli B, Grin J et al. (2000) Food habits and sport activity during adolescence: differences between athletic and non-athletic teenagers in Switzerland. Eur J Clin Nutr 54, S16-S20.

51. Robbins LB, Sikorskii A, Hamel LM et al. (2009) Gender comparisons of perceived benefits of and barriers to physical activity in middle school youth. Res Nurs Health 32, 163-176.

52. Gibson GJ (2000) Obesity, respiratory function and breathlessness. Thorax 55, Suppl. 1, S41-S44.

53. Ekelund U, Neovius M, Linne Y et al. (2005) Associations between physical activity and fat mass in adolescents: the Stockholm Weight Development Study. Am J Clin Nutr 81, 355-360.

54. McMurray RG, Ward DS, Elder JP et al. (2008) Do overweight girls overreport physical activity? Am J Health Behav 32, 538-546.

55. Neumark-Sztainer D \& Hannan PJ (2000) Weight-related behaviors among adolescent girls and boys - results from a national survey. Arch Pediatr Adolesc Med 154, 569-577.

56. Kuchler F \& Variyam JN (2003) Mistakes were made: misperception as a barrier to reducing overweight. Int $J$ Obes 27, 856-861.

57. Paeratakul S, White MA, Williamson DA et al. (2002) Sex, race/ethnicity, socioeconomic status, and BMI in relation to self-perception of overweight. Obes Res 10, 345-350.

58. Paccaud F, Wietlisbach V \& Rickenbach M (2001) Body mass index: comparing mean values and prevalence rates from telephone and examination surveys. Rev Epidemiol Sante Publique 49, 33-40.

59. Fonseca H, de Matos MG, Guerra A et al. (2009) Emotional, behavioural and social correlates of missing values for BMI. Arch Dis Child 94, 104-109. 